\title{
DEMOCRACIA E CUIDADO EM SAÚDE MENTAL: ATRAVESSAMENTOS ÉTICOS E POLÍTICOS
}

Andressa Mayara Silva Souza

Universidade Federal do Recôncavo da Bahia

Rafael Coelho Rodrigues

Universidade Federal do Recôncavo da Bahia
Recebido em: 03/07/2019

$1^{\text {a }}$ revisão em: 06/01/2020

Aceito em: 25/02/2020

\section{RESUMO}

O presente trabalho objetiva apresentar uma articulação entre os campos da saúde e da política, de modo a indicar a forma como cada um define e enquadra alguns de seus conceitos e, sobretudo, suas práticas. A noção de Psicologia aqui operada supera a produção de uma psicologia da representação que retira as possibilidades de singularização, para pensar em uma psicologia da diferença, que questiona os saberes/poderes instituídos. Conclui-se, nessa linha de considerações, com a importância de afirmação de uma perspectiva democrática de acesso aos serviços de saúde e participação ativa dos usuários nos modos de produção de cuidado. Defende-se, portanto, uma clínica a ser construída e reinventada a partir do encontro com os(as) usuários(as).

Palavras-chave: psicologia; democracia; saúde mental. 


\section{DEMOCRACY AND MENTAL HEALTH CARE: ETHICAL AND POLITICAL CROSSINGS}

\section{ABSTRACT}

The present work aims to present the interdisciplinarity between health and political fields, in order to indicate how each defines and fits some of its concepts and, above all, its practices. The notion of Psychology here operated surpasses the production of a psychology of representation that removes the possibilities of singularization, to think of a psychology of difference, that questions the knowledge/powers instituted. It is concluded, in this line of considerations, with the importance of the affirmation of a democratic perspective of access to health services and active participation of users in the modes of care production. Therefore, it is advocated a clinic to be build and reinvented from the meeting with the users.

Keywords: psychology; democracy; mental health.

\section{DEMOCRACIA Y CUIDADO EN LA SALUD MENTAL: CRUCES ÉTICOS Y POLÍTICOS.}

\section{RESUMEN}

El presente trabajo objetiva presentar la interdisciplinaridad entre los campos de la salud y de la política, para indicar la forma como cada uno define y enmarca algunos de sus conceptos y, sobre todo, sus prácticas. La noción de Psicología aquí operada supera la producción de una psicología de la representación que retira las posibilidades de singularización, para pensar en una psicología de la diferencia, que cuestiona los saberes/poderes instituidos. Se concluye, en esta línea de consideraciones, con la importancia de la afirmación de una perspectiva democrática de acceso a los servicios de salud y la participación de los usuarios en los modos de producción de la atención. Por lo tanto, se recomienda construir y reinventar una clínica a partir de la reunión con los usuarios.

Palabras clave: psicología; democracia; salud mental. 


\section{INTRODUÇÃO}

\section{PSICOLOGIA, CLÍNICA, TERRITÓRIO E MODOS DE SUBJETIVAÇÃO: ALGUMAS FERRAMENTAS CONCEITUAIS.}

Desde o golpe parlamentar-midiático-empresarial de 2016 e o atual contexto de ameaça à tão jovem democracia brasileira, é notório perceber a urgência de uma luta contra os regimes autoritários, sobretudo, em virtude dos atravessamentos éticos e políticos destes no fazer psi e nos modos de produção da subjetividade. Para tanto, o presente trabalho propõe um retorno a algumas ferramentas conceituais que se articulam a esta construção, de modo a questioná-las por meio de outras composições possíveis. Justifica-se o presente trabalho na tentativa de tensionar conceitos naturalizados de modo a contribuir para uma Psicologia radicalmente comprometida com a democracia e com políticas e práticas pautadas pela inclusão e justiça social. Assim, o conceito mesmo de subjetividade há de ser retomado, relacionando-o a proposições outras como as noções de psicologia, clínica, território e subjetividade/modos de subjetivação. Em uma segunda análise, apresentaremos um breve ensaio a respeito do tema da democracia, partindo do pressuposto desta enquanto um princípio que transversaliza, de modo geral, os primeiros conceitos aqui mencionados. Como terceiro ponto de discussão, utilizaremos a política de cuidado aos usuários de substâncias psicoativas como analisador da articulação entre estes conceitos e seus efeitos éticos e políticos no contemporâneo.

Comecemos, então, pelo conceito de subjetividade. Tendo em vista a complexidade que se insere na discussão, serão utilizadas como referências as ideias trazidas por Guattari (1992, p.19), em Caosmose, onde define subjetividade como "o conjunto das condições que torna possível que instâncias individuais e/ou coletivas estejam em posição de emergir como território existencial, auto referencial, em adjacência ou em relação de delimitação com uma alteridade ela mesma subjetiva".

Tal elaboração apresenta uma série de outros conceitos que, dispostos em relação, inscreve a subjetividade na dimensão daquilo que só pode ser apreendido por uma via coletiva da produção constante e emergente de diferenciações. Via de regra, a subjetividade pode ser compreendida enquanto um processo de produção, ou um conjunto de condições por meio das quais são construídos efeitos existenciais, sempre de forma coletiva e contínua. Dito de outro modo, essa compreensão instaura a possibilidade principal de ruptura dos modos essencialistas de estudo da subjetividade. Além disto, compreende-se que a subjetividade pode ser composta por intermédio de dois processos, em que um se dá pela via de um assujeitamento às normatividades subjetivas - produção de subjetividades capitalísticas - e em outro, que se produz pela expressão e criação de componentes subjetivos, engendrando outros novos territórios existenciais. Assim, por meio de uma perspectiva não identitária da subjetividade, compreende-se tal processo como aquilo que é forjado incessantemente 
mediante a multiplicidade e dos efeitos entre os desejos, os corpos e as intensidades afetivas.

Vale mencionar ainda que toda subjetividade se encontra estruturada também a partir de um aspecto central: o tempo. Reconhecer a subjetividade em sua dimensão histórica e temporal implica a reconstrução da compreensão mesma que se tem do tempo. Se o tempo em Foucault é demarcado sob o aspecto de uma não rigidez, seus eixos historicamente constituídos tendem a desfazer-se, de modo que outros tempos se engendram e, como consequência, outros modos de subjetivação. Sob essa afirmação, falar de subjetividade em uma perspectiva foucaultiana convoca-nos a reconhecê-la em uma via de mobilidade e não linearidade frente às modulações colocadas pelo tempo. Via de regra, para Foucault, a subjetividade não pode ser concebida de modo fixo e rígido. Por outro lado, tal como exposto por Cardoso (2015), em uma perspectiva que envolve um modo de vida, tal compreensão da subjetividade supõe um corpo que se movimenta de encontro a uma heterogeneidade de elementos que se compõem e se disjuntam a partir do tempo, ao contrário de identidades fixas sob produções discursivas de saber.

Ainda em Foucault (1995), a respeito dos modos de subjetivação, observamos que onde há o exercício do poder há resistência e possibilidade de luta, pois "se é verdade que no centro das relações de poder e como condição permanente de sua existência, há uma 'insubmissão' e liberdades essencialmente renitentes, não há relação de poder sem resistência, sem escapatória ou fuga" (Foucault, 1995, p. 248). Para Foucault (1995), não se trata de um movimento de resistência contra a dominação ou contra a exploração, trata-se mais precisamente, do poder que se aplica no cotidiano dos sujeitos, que os torna submissos à sua própria individualidade.

Nesse sentido, falar de subjetividade significa falar também dos modos de produção subjetiva - ou modos de subjetivação - que, paralelamente, são engendrados. Para tanto, é necessário recorrer a Foucault. Tomando o corpo como realidade política por excelência, Foucault (1975) investiga os modos por meio dos quais o poder incide sobre os corpos, instaurando efeitos de subjetividade nestes. Aqui, o que interessa demarcar, é o modo como nas práticas cotidianas "as relações de poder penetram os corpos" (Foucault, 1994, p. 228), tecendo organismos e modos de subjetivação produtivamente úteis e dóceis. Dessa forma, são construídos modos de subjetivação específicos, individualizados e serializados, de modo que a própria produção de subjetividade - e sobretudo de desejos - se torne a base do capital. Não há capitalismo sem esta produção de subjetividades. Nesse sentido, a produção mesma da subjetividade opera por intermédio da tentativa constante de eliminação dos processos de singularização. Por outro lado, tais processos "(r)existem" às capturas, por meio de transformações outras, podendo construir novos modos possíveis de ocupar o mundo e criar singularizações outras no socius ${ }^{1}$. 
Para tanto, é necessário pensar no cenário de encontro desses modos de subjetivação, a saber, no território - também subjetivo - que permite tais construções. Nessa outra operação conceitual, é possível pensar o território de outras formas. Não se trata mais apenas de um espaço geográfico e estático. Há de se pensar no território enquanto um corpo heterogêneo, dinâmico e relacional. Um meio que comporta, ao mesmo tempo, a produção da diferença, do que escapa à homogeneidade, aos processos mais rígidos de singularização. É, sobretudo, um território de vida, desejos, afetos, da heterogeneidade e composição destes.

A perspectiva de território aqui apresentada supera a noção de uma delimitação geográfica, visto que, conforme Guattari e Ronilk (2010)

O território pode ser relativo tanto a um espaço vivido, quanto a um sistema percebido no seio do qual um sujeito se sente "em casa". O território é sinônimo de apropriação, de subjetivação fechada sobre si mesma. Ele é o conjunto de projetos e representações nos quais vai desembocar, pragmaticamente, toda série de comportamentos, de investimentos, nos tempos e nos espaços sociais, culturais, estéticos, cognitivos (p. 388).

É a partir desta noção de território e processos de subjetivação que uma outra clínica será necessária e, ao mesmo tempo, possível. Aqui, a clínica se apresenta pela via transdisciplinar de uma experiência dos afetos e de um modo de acompanhar as modulações existenciais e subjetivas. A clínica opera de modo eminentemente político, de modo que produz bifurcações na existência e acompanha as práticas discursivas desta em sua dimensão criativa. Para tanto, é necessário pensar a clínica a partir de suas modulações, daquilo que se dá em um "entre-domínios". Além disto, se partimos do pressuposto da subjetividade enquanto um processo constante de (des)territorialização, cabe a clínica acompanhar esses fluxos e, por que não, desestabilizá-los. Trata-se, sobretudo, de uma clínica que cria possibilidades de composições estéticas, afetivas, existenciais, artísticas, subjetivas, éticas, políticas e desejantes. Uma clínica utópica: clínica sem lugar. Conforme sinalizado por Passos e Benevides (2006), esta clínica utópica, a clínica transdisciplinar, "se apresenta como uma experiência com os afetos" (p. 2), de modo que

O trabalho da clínica é o de acompanhar os movimentos afectivos da existência construindo cartas de intensidade, ou cartografias existenciais que registram menos os estados do que os fluxos, menos as formas do que as forças, menos as propriedades de si do que os devires para fora de si (p.3). 


\section{O CONCEITO DEMOCRACIA: INCURSÕES EM OUTRAS GRAMÁTICAS}

Caracterizar a democracia enquanto um regime no qual a soberania pertence ao conjunto de cidadãos requer, com evidente cautela, algumas outras elaborações. A respeito disto, Rolnik (1995) afirma que há o hábito recorrente de considerar a conquista da democracia como alvo para a melhoria na qualidade das existências individuais e coletivas, que se torna difícil pensar que tal melhora deve implicar em algo para além de tal conquista, sobretudo em um país como o nosso. Tornase necessário, portanto, avançar um pouco mais.

Conforme ideias apresentadas por Rancière (2014) em seu livro "O Ódio a Democracia", haveria uma lógica de produção da democracia enquanto forma de governo, de modo que tal lógica impossibilitaria, paradoxalmente, o próprio exercício democrático nas sociedades contemporâneas. Umas das críticas trazidas pelo autor diz respeito a uma forma de democracia que quer que todos sejam iguais e tenham suas diferenças respeitadas, produzindo o que ele denominou de individualismo democrático. Contudo, a produção do individualismo - favorável às elites - torna-se ineficiente, uma vez que inviabiliza as possibilidades de crítica aos modos de governo e legitima escolhas de intolerância e/ou exclusão, reafirmando cotidianamente o discurso de que se vive em uma democracia e, para tanto, todas as opiniões devem ser respeitadas.

Nesse sentido, a ideia de individualismo democrático pode se articular ao que é exposto por Rolnik (1995) quando diz da dificuldade para lidar com aquilo que é da ordem da alteridade. Conforme apresentado pela autora, há a produção de um homem moral que se estrutura pela resistência ao encontro com o outro; resistência à dimensão invisível da alteridade. De acordo com Rolnik (1995), essa dimensão

é o que extrapola nossa identidade - essa unidade provisória onde nos reconhecemos -, [...] na qual se operam permanentemente novas composições que, a partir de um certo limiar, provocam turbulência e transformações irreversíveis no atual contorno de nossa subjetividade (p. 4).

Nesse sentido, a alteridade é aquilo no qual o homem moral não consegue estar sensível suficiente para permitir-se ser afetado. Pensando nas ressonâncias disso no individualismo democrático, percebe-se a produção de uma ilusão por um mundo estável, em virtude impossibilidade deste indivíduo para lidar com o caos e o devir. Disto, resta o sentimento que cabe a cada um defender seus ideais individuais de modo "democrático e livre", no intuito de não permitir que as certezas sejam atravessadas pelo encontro com o outro - esse outro que é caos, devir e ameaça. 
Tal discurso se articula ainda às ideias subjacentes ao liberalismo, na medida em que produz uma confusão na concepção de democracia enquanto possibilidade para escolher representantes, por meio da liberdade do voto secreto, direto e universal. Nesse sentido, a democracia deixa de ser um princípio que atravessa de forma vital a sociedade e se reduz à "liberdade de escolha". O problema que se coloca em tal produção é que ter liberdade conduz à possibilidade de errar e de produzir a desordem mesma da democracia. De modo contraditório, a democracia representativa liberal impossibilita o seu próprio exercício. Além disso, a problemática de pensar a democracia enquanto uma forma efetiva de eleger os representantes da maioria se coloca no fato de que, por vezes, esta maioria é corrompida pelos próprios instrumentos ditos democráticos - como a mídia, por exemplo -, na medida em que a realidade da lógica do capitalismo liberal e se impõe como algo anterior a toda existência; como aquela que estrutura e funda os modos de subjetivação aí produzidos. Na medida em que a ideologia liberal submete todas as vidas às exigências do lucro capitalista, não se torna possível falar em uma autonomia dos cidadãos. Consequentemente, produz-se o regular declínio da democracia.

Tal declínio pode ser constatado na tese apresentada por Rancière (2014) quando sinaliza que há um engano no que se entende atualmente por democracia. De acordo com o autor, o princípio democrático não pode jamais se identificar à forma de um Estado: "a democracia é apenas uma forma de vida na sociedade e não uma forma de estado, o estado ainda é oligarca, ou seja, o poder na mão dos ricos" (Rancière, 2014, p. 60). Nesse sentido, o objetivo representativo se torna falho e não condiz com o que, de fato, poderia ser a democracia. Nessa perspectiva, Levitsky e Ziblatt (2018) afirmam que o declínio da democracia pode se dar não de forma autoritária e direta, mas por intermédio dos próprios líderes eleitos. De acordo com os autores, a ditadura ostensiva desapareceu na maior parte do mundo, de modo que os golpes militares e as tomadas violentas tornaram-se raros, assumindo outra característica:

$\mathrm{Na}$ via eleitoral, nenhuma dessas coisas acontece. Não há tanques nas ruas. Constituições e outras instituições nominalmente democráticas restam vigentes. As pessoas ainda votam. Autocratas eleitos mantém um verniz de democracia ao mesmo tempo que corroem a sua substância. Muitos esforços do governo para subverter a democracia são "legais", no sentido de que são aprovados pelo Legislativo ou aceitos pelos tribunais. Eles podem até mesmo ser retratados como esforços para aperfeiçoar a democracia. (p. 9).

Ainda de acordo com Levitsky e Ziblatt (2018), o discurso de "combate à corrupção legitimado pela mídia acaba por criar perplexidade e confusão nas pessoas, de modo que o declínio da democracia se dá sem um momento único, "nenhum golpe, declaração de lei marcial ou suspensão da Constituição" (p. 9), uma vez que nesses cenários nada é capaz de disparar a sociedade para o 
questionamento. A democracia tem sua queda, nesse sentido, de forma democrática. Conforme apontado pelos autores, "o paradoxo trágico da via eleitoral para o autoritarismo é que os assassinos da democracia usam as próprias instituições da democracia - gradual, sutil e mesmo legalmente- para matá-la" (Levitsky \& Ziblatt, 2018, p.11). Para tanto, é importante questionarmonos se, de fato, há o exercício de uma democracia atualmente e se esta efetiva-se de modo representativo.

Nesta mesma linha de considerações, Boaventura de Sousa Santos (2002) sinaliza a possibilidade de uma perspectiva democrática participativa; uma proposta que se apresenta no campo das teorias não-hegemônicas, como uma alternativa de emancipação social pela transformação das relações de poder em relações de autoridade compartilhada. Portanto, constitui-se também como viabilidade de radicalização da democracia - e tem seus pontos de aproximação com a perspectiva democrática radical de Laclau - na medida em que "intensifica sua tensão com o capitalismo" (Santos, 2002, p. 126). Além disto, ao afirmar que vivemos em sociedade que são politicamente democráticas, mas socialmente fascistas, Santos (2002) aponta para a dimensão micropolítica do fenômeno, uma vez que retira seu foco de análise dos domínios considerados políticos, para centrar-se nas relações de poder que se dão em outros domínios (nas fábricas, casas, comunidades e no mercado), denominados "espaço-tempo". A partir destes, Santos (2002) demonstra que pouco é democrático nas sociedades ditas democráticas. De acordo com o autor

Como a vida dos indivíduos, das classes ou dos grupos sociais decorre em domínios considerados não políticos, na medida em que neles domina o fascismo social, a democracia representativa tende a ser sociologicamente uma ilha democrática num arquipélago de despotismos (p.132).

Neste sentido, Santos (2002) define a democracia como o processo de transformação das relações desiguais de poder nos âmbitos de partilha de autoridade. Para a superação dessa desigualdade e do poder que se dá em forma de constelação - sobretudo nos modos de subjetivação -, há a necessidade, portanto, de uma constelação de resistências, que possibilite a emancipação social de todos os atores envolvidos. Em síntese, a crítica ao modelo democrático liberal colocado por Boaventura de Sousa Santos não se reduz à ausência de democracia, mas no fato de sua insuficiência. A transformação da democracia se faz possível por uma via participativa que extrapola a participação política e vai além do exercício do voto. É a construção de uma cultura política de transformação cotidiana da autonomia das coletividades.

Ao indicar uma possibilidade de democracia "real" em tempos nos quais a liberdade e a igualdade não são mais representadas nas instituições e na lei do Estado, Rancière (2014) caracteriza a democracia enquanto princípio que vitaliza as instituições, no sentido de que esta poderia ser exercida como uma forma de 
vida, como uma força exercida de variadas formas, no intuito de se opor à tendência oligárquica de qualquer poder. Neste sentido, na medida em que a extensão democrática diminui, a participação social tem sua queda, de modo que a implementação de políticas públicas realmente necessárias também é afetada. Articula-se a isso o fato de que a diminuição da vulnerabilidade pode se efetivar por meio do fortalecimento dos sujeitos no acesso aos direitos que tais políticas devem ofertar (Rodrigues, no 2016).

Isso vem ao encontro do que é exposto por Rolnik (1995), quando faz notar que a democracia se torna possível e somente se reinventa por meio da luta contra a resistência à diferenciação. Tendo em vista os conceitos aqui apresentados e o atual cenário antidemocrático vigente no país, apresentaremos a seguir uma análise dos atravessamentos colocados por tal contexto nas possibilidades de cuidado aos usuários de substâncias psicoativas, de modo a melhor compreender, politicamente, os efeitos destes nos modos de subjetivação.

\section{A POLÍTICA DE CUIDADO AO USUÁRIO DE SUBSTÂNCIA PSICOATIVA COMO ANALISADOR DE PRÁTICAS PSI VOLTADAS PARA UM DESEJO POR DEMOCRACIA}

Nas últimas décadas observa-se que o tema sobre o cultivo, a venda e o consumo de substâncias psicoativas se tornaram um dos grandes pontos de debate em nossa sociedade. A partir dos anos oitenta com o declínio da guerra fria, uma política de guerra às drogas começa a ser implementada pelos Estados Unidos e pela ONU. No Brasil, saído recentemente de um período de ditadura civil militar e com sua herança escravista e de naturalização da desigualdade social, a guerra às drogas se torna rapidamente uma guerra à determinados segmentos da população que produzem, vendem ou consomem substâncias específicas. Assim, percebemos como esta política funciona como um dispositivo que possibilita no final do século XX e início do XXI uma atualização do racismo de Estado por meio do qual se torna possível em uma época na qual mais defendemos a vida, denominada por Foucault como biopoder, deixar uma parcela da população morrer (Foucault, 2006), ou até mesmo, implementar em determinadas regiões uma política estatal deliberada de fazer morrer, conforme apontou Mbembe a partir do conceito de necropolítica (Mbembe, 2018).

Conforme colocado nesta teorização, o historiador e cientista político Achille Mbembe afirma que os efeitos do biopoder se traduzem na passagem da biopolítica para a produção de uma necropolítica. De acordo com Mbembe (2003), não se trata mais de uma política voltada para a produção da vida, e sim uma política cujo objetivo é - em virtude da legitimidade do direito de matar - a aniquilação em larga escala. Ao falar da soberania enquanto um direito de matar, Mbembe (2003) aponta que "o Estado empreende a tarefa de civilizar as formas 
de assassinar e atribuir objetivos racionais ao ato mesmo de matar" (p.38). Dessa forma, mediante a premissa do direito de matar, a necropolítica produz um largo processo de desumanização e industrialização da morte, transformada em um procedimento puramente técnico, silencioso, rápido e impessoal (Mbembe, 2003).

Chega-se ao final da segunda década do século XXI, com a estatística exorbitante de jovens negros, pobres e da periferia das cidades brasileiras ${ }^{1}$ mortos em virtude desta guerra. Além da morte destes jovens a partir da política de guerra às drogas, outro dado alarmante é o número destes que, hoje, encontram-se desaparecidos. O desaparecimento forçado foi uma das tecnologias de controle social construída pela ditadura brasileira e que permanece atualmente, assim como o uso como subterfúgio de autos de resistência para encobrir a política pública de extermínio desta parcela da juventude brasileira. No âmbito dessas produções, a guerra às drogas só é possível quando se associam as substâncias psicoativas ao mal e classificam-se seus usuários ora como pecadores, ora como criminosos, ora como doentes, ou um misto que congrega ambas denominações.

Observa-se que há, neste sentido, uma regulação seletiva da vida de alguns em detrimento de outros enquanto efeito desses mecanismos de segurança e da necropolítica. Dessa forma, o "fazer viver e deixar morrer" implica na defesa de determinados segmentos da população no interior do Estado Democrático de Direito, como colocado por Lemos, Aquime, Franco e Piani (2017). Cabe salientar, conforme sinalizado por Batista (2003), que o extermínio de indivíduos classificados como supostamente indignos de viver é um efeito da produção do racismo na sociedade de modo geral, sendo estes corpos hierarquizados segundo critérios morais e em escalas de valor, critérios normalizantes da política criminal do direito penal. De modo a ilustrar melhor tal prerrogativa, é possível considerar os assassinatos em larga escala de jovens negros nas periferias urbanas do Brasil. Conforme exposto por Lemos et al. (2017), de acordo com os dados do SIM/Datasus, em 53,37\% do número total de homicídios ocorridos no Brasil (56.337), as vítimas foram os jovens (30.072); destes, 77,0\% eram pretos e pardos, sendo 93,30\% do sexo masculino. Articulando esses dados com o exposto anteriormente, é possível tomar a hipótese de que há um modo específico de regular essas vidas e, portanto, há um modo específico também de reconhecer essas mortes.

Neste sentido, há uma regulação coletiva desses corpos a partir da separação destes em segmentos sociais mediante olhares e exames, produzindo uma categorização da multiplicidade humana por traços e comportamentos, local de moradia e escolaridade, profissão e cor da pele, pertencimento a uma cultura e a um tipo de família, pela comunidade onde está e pela faixa etária.

No campo das políticas assistenciais que se conectam ao paradigma de guerra às drogas que, na verdade, é uma guerra a jovens pobres e negros, há uma linha de continuidade a partir do viés da abstinência como mote terapêutico prescrito em 
todas as situações. Neste mesmo sentido, esta modalidade de cuidado prescreve a internação e, até mesmo, internações compulsórias e/ou involuntárias. Porém, a defesa de internações compulsórias e/ou involuntárias para determinados consumidores de substâncias psicoativas, atualmente, majoritariamente, para usuários/as de crack, precisa ser analisada numa perspectiva que demonstre como esta prática tem sido utilizada como instrumento de uma política higienista. Em outra publicação, foi possível demonstrar como a guerra aos usuários de crack no Brasil pré-Copa do Mundo de futebol e Olimpíadas funcionou como mecanismo para gestão de populações indesejáveis e para a gestão de territórios da cidade que a partir da internação e expulsão das populações que habitavam tais regiões, foi possível um reordenamento destes espaços urbanos, disponibilizando-os para a iniciativa público-privada e, posteriormente, possibilitando especulação imobiliária (Rodrigues, 2016).

Em detrimento a guerra às drogas e seus tentáculos nas políticas de assistência e cuidado aos usuários, como a abstinência como via de regra e internações involuntárias e compulsórias, a Política Nacional de Saúde Mental brasileira preconizada a partir da reforma psiquiátrica, indicava outra perspectiva de atenção que vislumbra-se aqui como mais próxima de uma sociedade pautada pelos valores democráticos e aos diferentes modos de vida possíveis numa democracia. A prática da redução de danos se opõe à abstinência, embora não seja antagônica, pois, numa perspectiva de reduzir os riscos e danos de um consumo abusivo de determinada substância, a redução de danos prevê que em determinadas situações, a abstinência possa ser necessária. Porém, a linha de cuidado ao usuário é construída com ele, percebendo que sua vida e suas necessidades de saúde vão além do uso/abuso da substância. Construir o vínculo com o/a usuário/a, muitas vezes, nos próprios locais de uso, é contribuir para o protagonismo e autonomia do usuário em relação ao acompanhamento e a sua vida. Entende-se, a partir disso, que as políticas de cuidado ao abuso de substâncias psicoativas são necessariamente, intersetoriais, pois, precisam articular ações de habitação, assistência social, saúde, educação, esporte e lazer, trabalho e renda - colocando o princípio da integralidade em evidente relação com uma produção democrática do cuidado em saúde.

Ao se relacionar com o usuário da substância com a perspectiva intersetorial de cuidados, o que se abre a ele é a cidade. Ele passa a ter direito a cidade. A guerra às drogas dificulta aos usuários abusivos das substâncias que acessem serviços de saúde, pois esta guerra produz o usuário como doente, pecador e criminoso, ao mesmo tempo, potencializando o estigma que o usuário carrega. Acessar os serviços de saúde e possibilitar que estes funcionem a partir da necessidade e demanda dos usuários é vivenciar, cotidianamente, a democracia buscada na sociedade. A possibilidade de que o público se torne de fato um serviço público, a partir da relação que este tece com o usuário, faz com que o público se torne uma metodologia, um caminho a ser percorrido e implementado no cotidiano. Isto é direito a cidade. Cidade vista como portal para os bens comuns da sociedade. Prática democrática. 
Porém, em junho de 2019, foi aprovada a lei 13.840 que dispõe sobre as condições de atenção aos usuários ou dependentes de drogas e trata do financiamento das políticas sobre drogas (Presidência da República. Subchefia para Assuntos Jurídicos, 2019). A abstinência passa a ser a prerrogativa que direciona a política de atenção ao uso/abuso de substâncias psicoativas. A lei estabelece também a possibilidade de maior financiamento das comunidades terapêuticas, mesmo depois da divulgação do relatório da inspeção nacional nestes estabelecimentos realizado pelo Ministério Público Federal em parceria com o Conselho Federal de Psicologia. O documento relata uma série de violações aos direitos humanos em todas as unidades visitadas.

Segundo o relatório da inspeção, foram encontrados até casos de trabalhos forçados - além de instalações precárias, contenção de pessoas à força, falta de profissionais de saúde e agressões físicas. Além disso, o relatório apontou também violação da liberdade religiosa das pessoas tratadas, com pacientes que se recusavam a participar da rotina de orações sendo punidos com trabalho forçado, chamado nas comunidades de "laborterapia". Esta lei estava em tramitação há seis anos no Congresso e encontrou no atual momento em que vivemos, uma conjuntura favorável para sua aprovação. Assim, entendemos que a legislação sobre atenção a população usuária de substâncias psicoativas pode operar como dispositivo de análise da capilaridade democrática em nosso país na atualidade, assim como, as necessárias articulações teórico-práticas que a psicologia precisa realizar para estar à altura do desafio de resistir a onda conservadora, neoliberal e higienista do presente.

\section{CONSIDERAÇÕES INCONCLUSIVAS}

\section{... Sobre reinventar as práticas psi}

Em articulação com os fundamentos e as possibilidades de cuidado colocados pela Política Nacional de Saúde Mental que era preconizada pela reforma psiquiátrica brasileira, retornemos às ferramentas conceituais aqui apresentadas. Partindo daquilo que se dá neste não-lugar, a clínica, o território e os modos de subjetivação impõem, politicamente, um outro modo de reconhecer a Psicologia. Em primeira análise, é necessário pensar de que forma o campo psi tem pactuado com os modos serializados de produção de subjetividade e o que, concomitantemente, tem legitimado em suas práticas, sobretudo em tempos de constantes demandas científicas pela regulação do sofrimento e da angústia.

Por outro lado, contrária às dicotomias mente/corpo, subjetivo/social, se faz necessária uma noção radical de Psicologia, que confronta e coloca em questão todas as suas demandas, certezas e essencialismos até então produzidos. Nessa linha de considerações, afirma-se uma perspectiva democrática de acesso aos serviços de saúde e participação ativa dos usuários nos modos de produção de cuidado. Tal noção supera a produção de uma psicologia da representação que retira as possibilidades de singularização, para pensar em uma psicologia da 
diferença, que questiona os saberes/poderes instituídos. Para tanto, é urgente habitar o lugar do imprevisível, fomentar outras formas de vida que não se deem estritamente pela via policialesca da razão. Em resumo, possibilitar uma Psicologia que se questione constantemente, de modo a potencializar as diferenças e imprevisibilidades da vida e, portanto, do processo de produção de subjetividades.

Retomando Rolnik (1995), cabe à subjetividade do "homem da moral" direcionarse para um outro vetor: o do "homem da ética". Este homem da ética, homem do inconsciente, volta-se para aquilo que se dá em um plano invisível da subjetividade. Torna-se agora sensível às reverberações das diferenças e consegue fazer outros possíveis frente às novas composições ou desconstruir composições vigentes. Em resumo, é o encontro sensível do inconsciente com a alteridade: democratização por excelência das subjetividades. Assim, neste trabalho defendemos que há uma clínica a ser construída a partir do encontro com estes/as usuários. E que esta clínica, no caso aqui específico, de uma clínica psi, somente será possível reinventando as práticas psi.

\section{REFERÊNCIAS}

Batista, V. M. (2003). Difíceis ganhos fáceis: Drogas e juventude pobre no Rio de Janeiro. Rio de Janeiro, RJ: Revan/IBCCRIM.

Cardoso, H. R., Jr. (2005). Para que serve uma subjetividade? Foucault, tempo e corpo. Psicologia: Reflexão e Crítica, 18(3), 343-349. doi:10.1590/S0102-79722005000300008

Cerqueira, D., Bueno, S., Lima, R. S., Neme, C., Ferreira, H., Alves, P. P., ... Armstrong, K. (2019). Atlas da violência 2019. Brasília, DF: IPEA.

Foucault, M. (1975-2009). Vigiar e punir: Nascimento da prisão (R. Ramalhete, Trad.). Rio de Janeiro, RJ: Vozes.

Foucault, M. (1995). O sujeito e o poder. In H. L. Dreyfus \& P. Rabinow (Eds.), Michel Foucault - uma trajetória filosófica - para além do estruturalismo e da hermenêutica (pp. 231-239). Rio de Janeiro, RJ: Editora Forense Universitária.

Foucault, M. (1994). Dits et écrits. Paris. Gallimard.

Guattari, F. (1992). Caosmose. São Paulo, SP: Editora 34.

Guattari, F., \& Rolnik, S. (2010). Micropolítica: Cartografias do desejo (10a ed.). Rio de Janeiro, RJ: Vozes.

Lemos, F. C. S., Aquime, R. H. S., Franco, A. C. F. \& Piani, P. P. F. (2017). O extermínio de jovens negros pobres no Brasil: Práticas biopolíticas em questão. Pesquisas e práticas psicossociais, 12(1), 164-176.

Levitsky, S., \& Ziblatt, D. (2018). Como as Democracias Morrem. São Paulo, SP: Zahar.

Nascimento, M., Macedo, J., \& Bocco, F. (2006). Reinventando as práticas psi. Psicologia \& Sociedade, 18(1), 15-20. doi:10.1590/S0102-71822006000100003.

Mbembe, A. (2003). Necropolitics. Public Culture, 15(1), 11-40. doi:10.1215/08992363-15-1-11

Passos, E., \& Benevides, R. (2006). Passagens da clínica. In A. Maciel, D. Kupermann, \& S. Tedesco (Eds.), Polifonias: Clínica, Política e Criação (pp. 89-100). Rio de Janeiro, RJ: Contracapa.

Presidência da República. Subchefia para Assuntos Jurídicos. (2019). Lei $n^{\circ} 13.840$, de 05 de junho de 2019. Dispõe sobre o Sistema Nacional de Políticas Públicas sobre Drogas e as condições de atenção aos usuários ou dependentes de drogas e para tratar do financiamento das políticas sobre drogas. Brasília, DF.

Rancière, J. (2014). O ódio à Democracia. São Paulo, SP: Boitempo Editorial.

Rodrigues, R. C. (2016). O Conservadorismo moderado, as políticas públicas e nós, intelectuaismilitantesé-pesquisadores (O programa Crack é possível vencer como dispositivo de análise). (Relatório de Pós-doutorado). Universidade Federal Fluminense, Rio de Janeiro, Brasil. 
Rolnik, S. (1995). À sombra da cidadania: Alteridade, homem da ética e reinvenção da democracia. In M. C. R. Magalhães (Ed.), Na sombra da cidade (pp. 141-170). São Paulo, SP: Escuta.

Santos, B. S. (2002). Democratizar a democracia. Os caminhos da democracia participativa. Rio de Janeiro, RJ: Civilização Brasileira.

Souza, T. (2011). Constituição, segurança pública e estado de exceção permanente: A biopolítica dos autos de resistência. (Tese de Doutorado). Pontifícia Universidade Católica do Rio de Janeiro, Rio de Janeiro, Brasil.

\section{CONFLTTOS DE INTERESSES}

Não há conflitos de interesses.

\section{SOBRE OS AUTORES}

Andressa Mayara Silva Souza é psicóloga pela Universidade Federal do Recôncavo da Bahia (UFRB). Pós-graduada em Fundamentos Teóricos e Clínicos da Psicanálise. No período de elaboração deste trabalho foi membro do Grupo de Pesquisa "Psicologia, Clínica, Território e Modos de Subjetivação: Democracia, acesso à cidade e atenção à saúde de populações vulnerabilizadas". Autora artigos na interface entre Saúde Mental e Psicanálise.

E-mail: andressa.mssouza@gmail.com

(1) https://orcid.org/0000-0003-2586-9725

Rafael Coelho Rodrigues é psicólogo pela Universidade Católica de Petrópolis e professor Adjunto do Centro de Ciências da Saúde - Universidade Federal do Recôncavo da Bahia - UFRB. Pós-doutor em Psicologia pela Universidade Federal Fluminense/UFF, doutor em Psicologia/UFF., e mestre em Psicologia pela Universidade Federal Fluminense. Autor dos livros: O Estado Penal e a Sociedade de Controle: O Programa Delegacia Legal como Dispositivo de Análise (ed. Revan, 2009) e Juventude como capital (Ed. Juruá, 2014). Pesquisador do Grupo de Pesquisa Produção de Subjetividade e Estratégia de Poder no campo da infância e da juventude (UERJ/UFF) e do Grupo de Pesquisa Saúde, Organizações e Trabalho (SORT/UFRB) e integrante do Centro de Referência Regional em Educação Permanente em Crack, Álcool e outras drogas (CRR/UFRB).

E-mail: rafaelcoelhopsi@hotmail.com

(3) https://orcid.org/0000-0002-9653-6154

\footnotetext{
${ }^{1}$ Socius: Conceito "não substantivo" elaborado por Deleuze e Guattari na obra "O Anti-Édipo", que expressa um modo de configuração que regula, desvia e configura de forma estável as modulações do desejo.

2 Segundo o Atlas da Violência de 2019, o número de jovens mortos no Brasil em 2017 foi de 35.783. O número representa uma taxa de 69,9 homicídios para cada 100 mil jovens no país, taxa recorde nos últimos dez anos.
} 